\title{
Sexual dimorphism and light/dark adaptation in the compound eyes of male and female Acentria ephemerella (Lepidoptera: Pyraloidea: Crambidae)
}

\author{
Ting Fan (Stanley) LaU ${ }^{1}$, Elisabeth Maria GROSS ${ }^{2}$ and Victor Benno MEYeR-ROCHOW ${ }^{1,3}$ \\ ${ }^{1}$ Faculty of Engineering and Sciences, Jacobs University Bremen, P.O.Box 750561, D-28725 Bremen, Germany \\ ${ }^{2}$ Limnological Institute, University of Konstanz, P.O. Box M659, D-78457 Konstanz, Germany \\ ${ }^{3}$ Department of Biology (Zoological Museum), University of Oulu, P.O.Box 3000, SF-90014 Oulu, Finland; e-mail: vmr@cc.oulu.fi \\ and b.meyer-rochow@iu-bremen.de
}

\begin{abstract}
Key words. Pyraloidea, Crambidae, compound eye, photoreception, vision, retina, sexual dimorphism, polarization sensitivity, dark/light adaptation, photoreceptor evolution
\end{abstract}

\begin{abstract}
In the highly sexual-dimorphic nocturnal moth, Acentria ephemerella Denis \& Schiffermüller 1775, the aquatic and wingless female possesses a refracting superposition eye, whose gross structural organization agrees with that of the fully-winged male. The possession of an extensive corneal nipple array, a wide clear-zone in combination with a voluminous rhabdom and a reflecting tracheal sheath are proof that the eyes of both sexes are adapted to function in a dimly lit environment. However, the ommatidium of the male eye has statistically significantly longer dioptric structures (i.e., crystalline cones) and light-perceiving elements (i.e., rhabdoms), as well as a much wider clear-zone than the female. Photomechanical changes upon light/dark adaptation in both male and female eyes result in screening pigment translocations that reduce or dilate ommatidial apertures, but because of the larger number of smaller facets of the male eye in combination with the structural differences of dioptric apparatus and retina (see above) the male eye would enjoy superior absolute visual sensitivity under dim conditions and a greater resolving power and ability to detect movement during the day. The arrangement of the microvilli in the rhabdom of both genders suggests that their eyes are polarization-sensitive, an ability they would share with many aquatic insects that have to recognize water surfaces. Although sexual recognition in $A$. ephemerella is thought to chiefly rely on pheromones, vision must still be important for both sexes, even if the females are wingless and never leave their watery habitat. Females swim actively under water and like their male counterparts, which fly above the surface of the water, they would have to see and avoid obstacles as well as potential predators. This, together with a small incidence of winged females, we believe, could be the reason why the eyes of female A. ephemerella are less regressed than those of other sexually dimorphic moths, like for instance Orgyia antiqua. Another, but difficult to test, possibility is that male and female A. ephemerella have diverged in their behaviour and habitat preferences less long ago than other sexually dimo rphic moths.
\end{abstract}

\section{INTRODUCTION}

With regard to morphological and biological characteristics insects are an enormously diverse taxon. The design features of the compound eye often reflect aspects of the life-style and phylogenetic relationships of an insect. Night-flying species like beetles and moths, for example, have compound eyes with larger ommatidia or wider clear-zones than daytime-active species (Caveney \& McIntyre, 1981; Jander \& Jander, 2002; Moser et al., 2004) and in certain Ephemeroptera, Lepidoptera, Coleoptera, and Diptera males are known to possess eyes with considerable regional specializations, for example, an "acute zone" of high acuity in the fronto-dorsal region of the eye for locating and tracking a mate (Hornstein et al., 2000; Merry et al., 2006).

In Lepidoptera, several species (all of them moths with very few exceptions, e.g. Nymphalidae: Viloria et al., 2003) have evolved that have micropterous females (i.e., females with reduced wings or no wings at all), but fully winged males (Hackman, 1966; Heppner, 1991). It has been speculated that the resources used for flight in the female could be re-allocated to fecundity (Roff \& Fairbairn, 1991). Zera \& Denno (1997) pointed out that the two genders are often contrasting with regard to their unique sets of distinctive behavioural and physiological adaptations. It could, therefore, be expected that the compound eyes of distinct morphs also have different visual tasks to master and, thus, may not only differ structurally from each other, but also function differently, for example, in response to exposures of light and dark conditions.

Studies of the compound eyes in the highly sexually dimorphic firefly Rhagophthalmus ohbai (Coleoptera: Rhagophthalmidae) (Lau \& Meyer-Rochow, 2006) and the moth Orgyia antiqua (Lau \& Meyer-Rochow, 2007) have revealed that the sedentary, wingless females have much smaller and less well-organized compound eyes than their male counterparts. As an extension of our earlier research, we now report ultrastructural details of the eyes and retinae of males and females of the aquatic moth Acentria ephemerella Denis \& Schiffermüller 1775 (see Denis \& Schiffermüller, 1775), a species formerly assigned to the Pyralidae, but nowadays placed in the Crambidae, Acentropinae (Speidel, 2003).

Acentria ephemerella is a small, nocturnally-active, aquatic moth native to Europe, but now also firmly established in North America (Berg, 1942; Batra, 1977; Buckingham \& Ross, 1981). The females have reduced wings and are incapable of flight. Fully-winged females, how- 
ever, also appear occasionally in the population. The rudimentary-winged females spend a considerable time of their lives in the water of ponds, lakes, and slow-moving streams and are able to swim by means of speciallyadapted middle and hind legs. At night they rest on the water surface and lift their abdomen into the air, releasing a pheromone to attract males.

Males, on the other hand, possess well-developed wings and fly closely above the surface of the water in search of the females (Berg, 1942; Batra, 1977; Buckingham \& Ross, 1981). Unlike most of the sedentary, micropterous females of other lepidopteran species, which possess an enlarged abdomen filled with eggs making flight difficult (Hackman, 1966), the reduction of the wing in $A$. ephemerella has been considered to represent an adaptive advantage for the moth to swim and oviposite underwater (Heppner, 1991). Thus, the mobile female A. ephemerella, despite their inability to fly, still need to see to avoid obstacles on their way to the water surface in order to mate or to find a suitable oviposition site. However, in view of the fact that female $A$. ephemerella spend most of their short adult life submerged under water, they may also need an eye that differs from that of the terrestrial and aerial male and more closely resembles that of a truly aquatic insect.

The larvae of $A$. ephemerella are efficient herbivores on submerged macrophytes (Gross et al., 2002) and might be considered an important biological agent in the control of the invasive macrophyte species Myriophyllum spicatum (Haloragaceae) (Batra, 1977; Johnson et al., 1998; Gross et al., 2001). Yet, no study dealing with the photoreceptors or vision in this moth has been forthcoming to date. Therefore, the aim of this paper has been to, firstly, investigate the general structural and ultrastructural differences of the compound eyes of male and female A. ephemerella and, secondly, describe any photomechanical changes in their eyes in response to changing ambient light intensities.

\section{MATERIAL AND METHODS}

\section{Light/dark adaptation experiments}

Pupae of Acentria ephemerella, attached to stems of a variety of aquatic weeds, were collected in the lower Lake Constance of southern Germany and transported to the International University Bremen in northern Germany, where they were kept in the laboratory at $16^{\circ} \mathrm{C}$ under a $14 \mathrm{~L}: 10 \mathrm{D}$ cycle. As the adults emerged from the pupae, they were subjected to different light intensities. To obtain, for example, fully daytime light-adapted (LA) individuals, the animals were exposed to daylight (but not direct sunlight) for at least $5 \mathrm{~h}$ prior to decapitation at noon $(12: 00 \mathrm{~h})$. Nighttime dark-adapted (DA) individuals were obtained by keeping the animals in total darkness for at least $5 \mathrm{~h}$ before decapitation at midnight $(24: 00 \mathrm{~h})$.

\section{Transmission and scanning electron microscopy}

The heads of the experimental specimens were split in half and fixed overnight at $4{ }^{\circ} \mathrm{C}$ in a mixture of $2 \%$ paraformaldehyde and $2.5 \%$ glutaraldehyde buffered to a $\mathrm{pH}$ of 7.4 with $0.1 \mathrm{M}$ sodium cacodylate. Following two washes in $0.1 \mathrm{M}$ cacodylate buffer, the specimens were then postfixed for one hour in $2 \%$ cacodylate-buffered $\mathrm{OsO}_{4}$ before being rinsed again in the same buffer and a wash in distilled water. The specimens were then dehydrated in a graded series of ethanol and immersed in acetone/Epon mixture for 1 day. Finally the specimens were embedded in Epon resin and hardened for 3 days at $60^{\circ} \mathrm{C}$. Semithin sections for light microscopy were cut on an ultramicrotome (model: "RMC") with a glass knife and stained with $0.5 \%$ toluidine blue on a hotplate. Ultra-thin sections were cut either with a glass or diamond knife and picked up on uncoated 300 mesh copper grids. The sections were then stained with Reynold's lead citrate for $20 \mathrm{~min}$ and $2 \%$ aqueous uranyl acetate for 15 min. Observations took place under a Zeiss EM 10 transmission electron microscope (TEM), operated at an accelerating voltage of $60 \mathrm{kV}$.

For observations by scanning electron microscopy (SEM), severed heads of the specimens were dehydrated in a graded series of acetone, air dried, and then sputter-coated with gold (EMI Tech, K550X) to a thickness of approximately $20 \mathrm{~nm}$. Examinations took place in a Jeol, JSM-5900 scanning electron microscope, operated at $20 \mathrm{kV}$.

\section{Morphometric analyses}

Specimens for scanning electron microscopy were used to determine width of the eye (distance from dorsal to ventral margin), facet diameters (i.e., the corner to corner distance of the hexagonal corneal surface) and total number of ommatidia per eye. Light micrographs of longitudinal sections were used for measurements of the corneal radius of curvature, interommatidial angle $(\Delta \varnothing)$, ommatidial length (distance from cornea to basement membrane), thickness of the cornea, cone length, clear-zone and rhabdom layer widths. Measurements of interommatidial distances, rhabdom areas in cross section and microvillus diameters were gathered from transmission electron micrographs of the mid-rhabdom region, where rhabdoms seemed maximally developed. Diameters of primary and secondary screening pigment granules were determined from transmission electron micrographs of sections through various regions of the eye.

In order to quantify and compare photomechanical changes in the compound eye, rhabdom occupation ratio (ROR) and relative clear-zone width (Meyer-Rochow \& Gál, 2004) were calculated from parameters measured on transmission electron and light micrographs. The ROR was calculated as follows:

$\mathrm{ROR}=$ rhabdom area/ total retinula cell area.

For each eye, at least 15 hexagonally arranged ommatidia were used for measurements on rhabdom areas and retinula cell diameters. The mean of all retinula cell diameters for a given eye was taken for the calculation of the retinula cell area. Values for relative clear-zone width (cz) were obtained through:

$\mathrm{cz}=$ width of clear-zone/ radius of curvature of the eye

Altogether three eyes of male and three of female individuals were used for measurements in connection with the SEM and 10 measurements were taken from each individual for each parameter. A total of 16 eyes from 16 individuals $(8$ male, 8 female) were examined by light and transmission electron microscopy and 3 to 5 eyes of either sex were used for observations in connection with the light-adapted condition. At least 5 , but most frequently 10 measurements were taken on each of the anatomical features. All of the morphological measurements were subjected to image-analysis software (W. Rasband: "ImageJ").

\section{Statistical analyses}

The "independent samples" t-test was used to test whether any statistically significant differences were present $(p<0.05)$ between male and female eyes. A "two-way" analysis of variance test (ANOVA) was performed to determine whether there were any statistically significant differences $(p<0.05)$ in the 

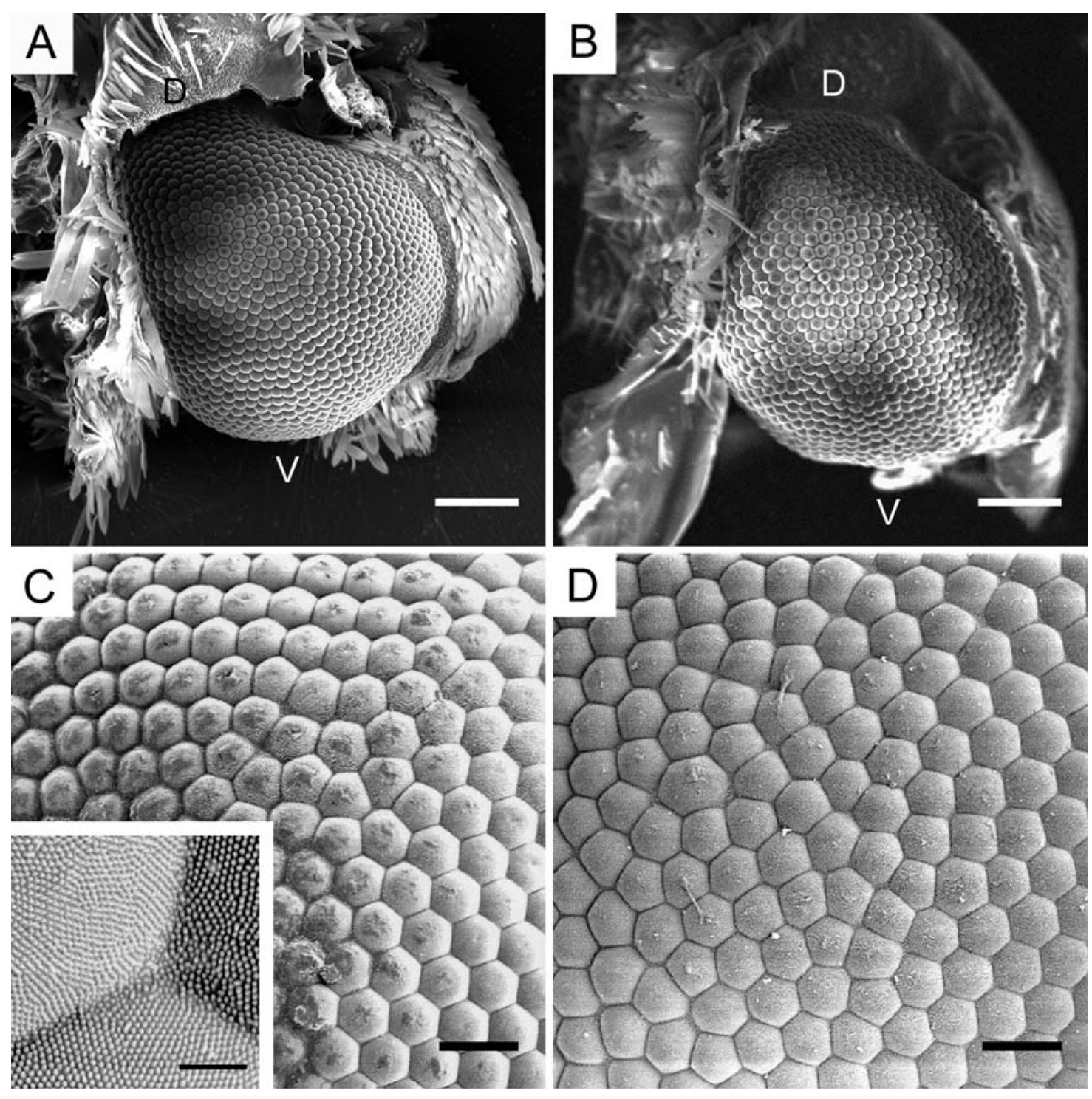

Fig. 1. Scanning electron micrographs of $A$. ephemerella compound eye. A, B - frontal view of the eye of male and female. Both sexes have a wider ventral region (V) and a narrower dorsal region (D). C, D - corneal facets of male and female. The male eye has somewhat smaller facets than the female, whose facets also appear to be less regularly arranged. The corneal surfaces of both eyes are covered with an array of corneal nipples (inset). Scale bars: A, B, $100 \mu \mathrm{m} ; \mathrm{C}, \mathrm{D}, 25 \mu \mathrm{m}$; inset, $2 \mu \mathrm{m}$.

effects of different light conditions between the two sexes. Statistical analyses were performed by using the SPSS statistical package programme.

\section{RESULTS}

\section{External anatomy of the male and female eye}

The compound eyes of both male and female Acentria ephemerella occupy lateral positions on either side of the head. Both male and female eyes resemble a water droplet, with the acute end pointing dorsally (Figs 1A, B). Maximum eye width in both sexes is $0.4 \mathrm{~mm}$. Male and female eyes have approximately 963 and 933 ommatidia, respectively (Table 1). Observations by SEM revealed that ommatidia are generally hexagonal in shape. The outer surfaces of the facets of both sexes are densely covered with corneal nipples, measuring $270 \mathrm{~nm}$ in height and $57 \mathrm{~nm}$ in diameter (Figs. 1C, D, Inset). However, there are no interfacetal hairs in either males or females.
Average facet diameters of male and female eyes measure $15.9 \mu \mathrm{m}$ and $17.3 \mu \mathrm{m}$, respectively, with facets of the male eye being significantly smaller than those of the female eye $(p<0.01$, Table 1$)$.

\section{General organization of the male and female eye}

The eyes of both sexes share the same overall cellular organization of the ommatidium. Each ommatidium features a dioptric apparatus, a clear-zone, 8 retinula cells that form a centrally-fused rhabdom and 1 basal cell (Figs $2-5)$. However, the two eyes differ from each other in a number of measurable morphological parameters. Ommatidial lengths of male and female eyes, for instance, measure 180 and $164 \mu \mathrm{m}$, respectively, but the difference did not reach statistical significance (Table 1). The radii of eye curvature, on the other hand, amounted to $272 \mu \mathrm{m}$ in male and $240 \mu \mathrm{m}$ in female eyes and were found to be statistically significant from each other $(p<0.05$; Table 
TABLE 1. Anatomical parameters of the eyes of male and female A. ephemerella.

\begin{tabular}{|c|c|c|c|c|c|}
\hline Parameter & Unit & $n$ & Male & Female & $p$ \\
\hline Number of facets per eye & - & 3 & $963 \pm 21$ & $933 \pm 27$ & NS \\
\hline Widest region of the eye & $\mu \mathrm{m}$ & 3 & $411 \pm 3.7$ & $421 \pm 22.42$ & NS \\
\hline Facet diameter & $\mu \mathrm{m}$ & 3 & $15.88 \pm 0.061$ & $17.32 \pm 0.24$ & $* *$ \\
\hline Eye radius of curvature & $\mu \mathrm{m}$ & 8 & $272.65 \pm 8.16$ & $240.63 \pm 10.02$ & $*$ \\
\hline Interommatidial angle & degree & 8 & $3.82 \pm 0.32$ & $4.13 \pm 0.26$ & NS \\
\hline Ommatidial length & $\mu \mathrm{m}$ & 8 & $180.97 \pm 6.73$ & $164.84 \pm 6.94$ & NS \\
\hline Dioptric apparatus & $\mu \mathrm{m}$ & 8 & $63.06 \pm 0.91$ & $56.88 \pm 1.50$ & $* *$ \\
\hline Corneal thickness & $\mu \mathrm{m}$ & 8 & $8.35 \pm 0.40$ & $7.41 \pm 0.28$ & $*$ \\
\hline Corneal outer radius & $\mu \mathrm{m}$ & 8 & $28.31 \pm 1.05$ & $27.96 \pm 1.49$ & NS \\
\hline Cone length & $\mu \mathrm{m}$ & 8 & $54.71 \pm 0.75$ & $49.48 \pm 1.45$ & $* *$ \\
\hline Clear-zone width & $\mu \mathrm{m}$ & 8 & $56.91 \pm 2.25$ & $45.18 \pm 2.99$ & $* *$ \\
\hline Relative clear-zone width & - & 8 & $0.21 \pm 0.011$ & $0.19 \pm 0.018$ & NS \\
\hline Rhabdom length & $\mu \mathrm{m}$ & 8 & $62.88 \pm 1.61$ & $54.74 \pm 1.14$ & $* *$ \\
\hline Rhabdom diameter & $\mu \mathrm{m}$ & 7 & $8.05 \pm 0.29$ & $7.75 \pm 0.18$ & NS \\
\hline Rhabdom cross-section area & $\mu \mathrm{m}^{2}$ & 7 & $45.11 \pm 2.81$ & $42.37 \pm 2.56$ & NS \\
\hline Rhabdom occupation ratio & $\%$ & 7 & $71.32 \pm 4.70$ & $65.17 \pm 5.39$ & NS \\
\hline Microvillus diameter & $\mathrm{nm}$ & 6 & $68.38 \pm 2.11$ & $70.41 \pm 2.26$ & NS \\
\hline
\end{tabular}

Data are expressed as mean \pm standard error and $n$ is the number of eyes measured. NS $=$ not significant, $*=p<0.05, * *=p<0.01$ in the independent samples t-test.

1). Some regional differences were apparent in both male and female eyes. The dorsalmost region in both male and female eyes had the smallest clear-zone and the shortest rhabdoms and, thus, appeared quite different from the rest of the eye. However, in terms of the cellular arrangements and general anatomical architecture this part was no different from the rest of the eye. Average inter-ommatidial angles of male and female eyes were found to be $3.8^{\circ}$ and $4.1^{\circ}$, respectively, but statistical significance was not reached.

As there were no statistical differences between the light- and dark-adapted eyes in all of the major morphological parameters studied (except screening pigment position and clear-zone width: see below), the morphometrical results based on the two adaptational states in the eyes of the same sex were pooled and treated as one data set. The dioptric apparatus of each ommatidium consists of the cornea and four cone cells. The corneal thicknesses of male and female eyes measure $8.4 \mu \mathrm{m}$ and 7.4 $\mu \mathrm{m}$, respectively, while corneal radii are $28.3 \mu \mathrm{m}$ in the male and $28.0 \mu \mathrm{m}$ in the female. Although corneal thickness was larger in males, the difference only just reached statistical significance, but the difference in corneal curvature did not (Table 1). The crystalline cone is of the eucone type and, as is the rule in other insects with this kind of cone, is secreted by four cone cells. Characteristic for the eucone type of eye is that the cone cell nuclei occupy the space between cornea and crystalline cone (Figs 2C, D, 3A). Cone lengths of the male measured $54.7 \mu \mathrm{m}$ and were, thus, found to be significantly longer than those of the female $(49.5 \mu \mathrm{m})(\mathrm{p}<0.01$, Table 1$)$. Transverse sections revealed that the cones were surrounded by 2 primary pigment cells and 4 to 5 secondary pigment cells, both types of cell containing innumerous pigment granules of high electron opacity (Fig. 3B). The sizes of the pigment grains of the primary and secondary pigment cells did not show any sex-specific differences and measured $0.65-0.7 \mu \mathrm{m}$ and $0.5-0.53 \mu \mathrm{m}$ in diameter, respectively.

The clear-zone separates the dioptric apparatus from the photoreceptor layer (Figs 2A-D). It measures $56.9 \mu \mathrm{m}$ in the eye of males and was found to be significantly wider than that of the eye of the females $(45.2 \mu \mathrm{m})(\mathrm{p}<0.01$; Table 1). Most of the interommatidial spaces in the clearzone are occupied by the extensions of the secondary pigment cells. In both sexes, each ommatidium contains a total of 9 retinula cells $(8$ regular retinula cells and 1 basal cell). The retinula cell bodies (identifiable through the presence of their nuclei) of cells R1-R8 occupy the distal side of the rhabdom layer below the cones. Their position is variable and depends on the adaptational state of the eye (Figs 2C-D) (see below). The retinula cell bodies of both male and female eyes also contain screening pigment granules (Fig. 3D), which measure $0.8-0.87 \mu \mathrm{m}$ in diameter. The 8 retinula cells form a slim retinula tract that traverses the clear-zone and then widens towards the distal end of the rhabdom (Figs 3C-D). Rhabdom formation occurs on the proximal side of the clear-zone. Rhabdoms are $62.9 \mu \mathrm{m}$ and $54.7 \mu \mathrm{m}$ long in male and female eyes, respectively, and were found to be statistically significantly different from each other $(\mathrm{p}<0.01$; Table 1$)$. Light micrographs of transverse sections revealed that the photoreceptor layer is almost entirely filled by the continuous layer of rhabdom material with hardly a separation between adjacent ommatidia (Figs 2E-F). A dense layer of air-filled tracheoles is responsible for the formation of a tapetum halfway down the rhabdom in both male and female eyes. The tracheal layer is extensive and continues below the basement membrane for approximately $18 \mu \mathrm{m}$ (Figs 2E-F, 5D). 

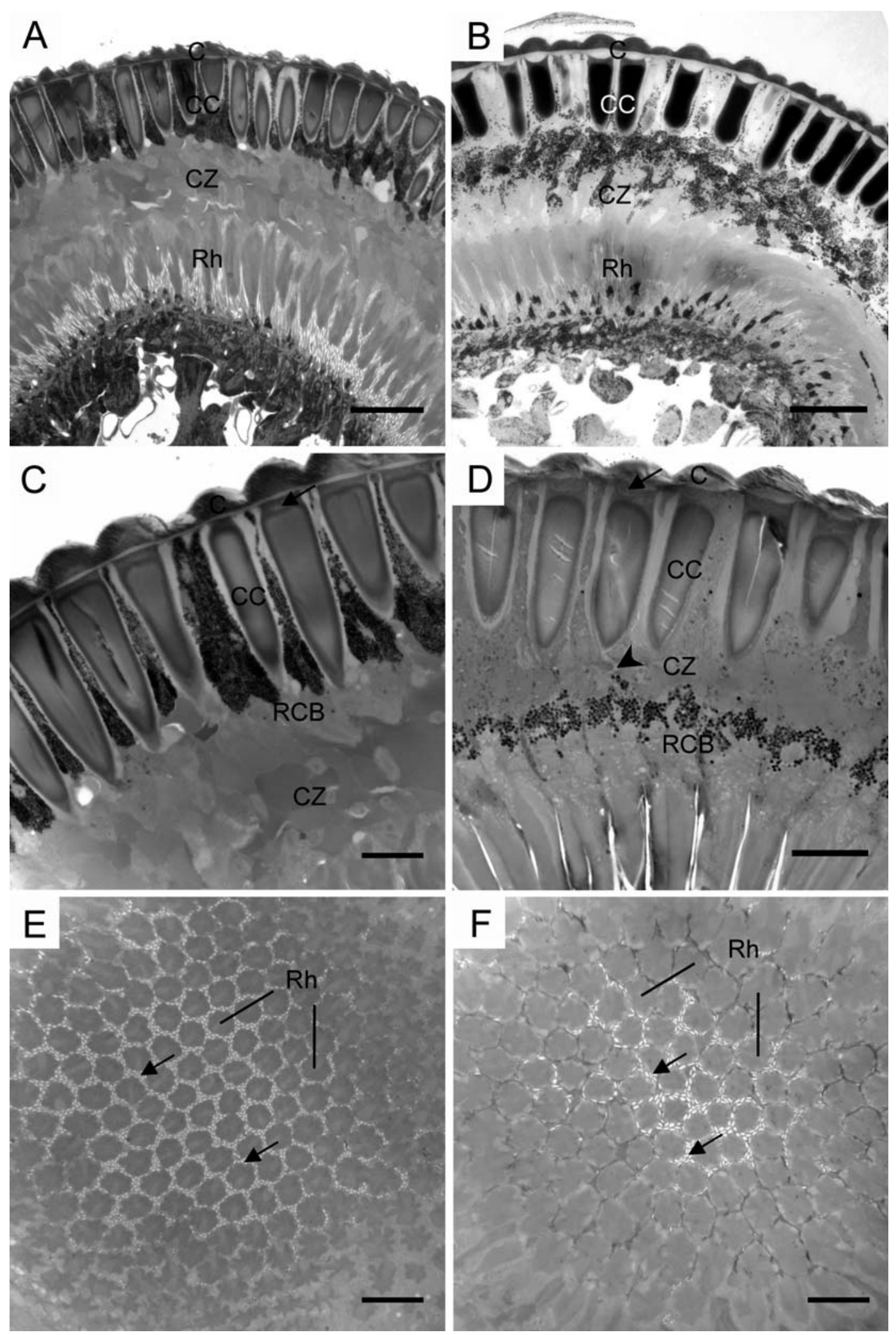

Fig. 2. Light micrographs of $A$. ephemerella compound eye. A, B - longitudinal sections, male. A - dark-adapted, B - lightadapted. Note the different positions of the screening pigments in both distal and proximal positions. The clear-zone (CZ) separates cornea (C) and crystalline cones (CC) from the rhabdom layer (Rh). C, D - dioptric apparatus. C - male, dark-adapted state; D female, light-adapted state. The dark-adapted eye shows the retinula cell bodies (RCB) in close approximation to the cone tips and screening pigment granules packed between the cones (CC). In the light-adapted eye, pigment granules have dispersed into the clearzone; the retinula cell bodies (RCB) have migrated proximally, leaving behind (in the region which they had occupied earlier) a crystalline cone tract (arrowhead), thus narrowing the aperture through which light can reach the receptors. The arrows indicate the location of the nuclei of the cone cells. E, F - transverse section through the retina with its rhabdoms (Rh) surrounded by a tracheal tapetum (arrows). E - male; F - female. In both the rhabdom forms an almost continuous layer. Scale bars: A, B, $50 \mu \mathrm{m}$; C-F, 20 $\mu \mathrm{m}$. 

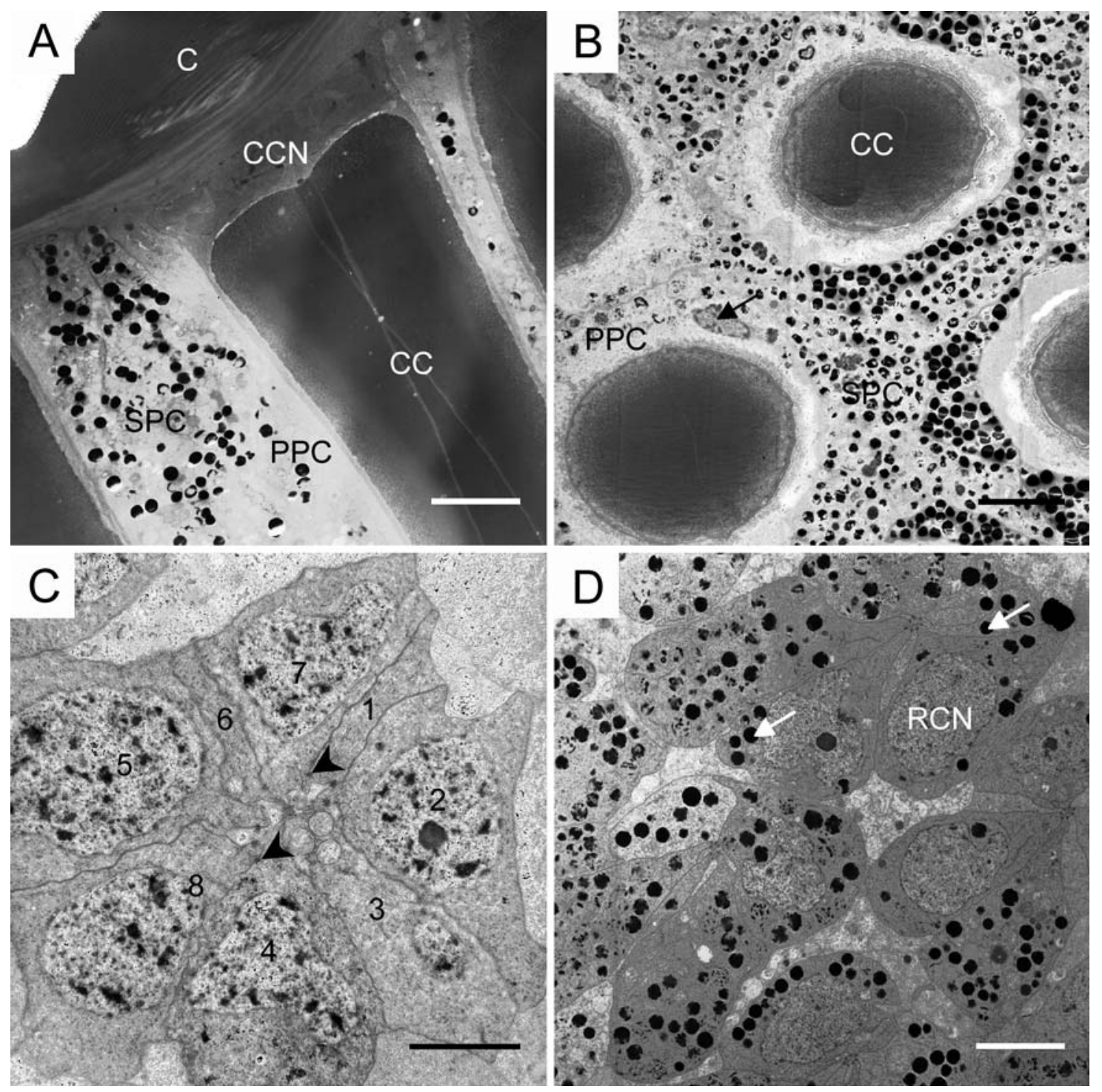

Fig. 3. Transmission electron micrographs of A. ephemerella compound eye. A, B - longitudinal and transverse section of the dioptric apparatus in the eye of the male, showing the lamellated cornea (C), the crystalline cone (CC), and the narrow cytoplasmic space that separates cornea and cone and contains the cone cell nuclei (CCN). The cones are always surrounded by two primary pigment cells (PPC) and several secondary pigment cells (SPC), both of which contain numerous electron-opaque pigment granules. The arrow in B indicates the nucleus of a primary pigment cell. C, D - transverse section through an ommatidial group of 8 retinula cells in male and female, showing retinula cell nuclei (RCN) and desmosomes (arrowheads). The white arrows point to screening pigment granules inside the receptor cells. Note that the retinula cell pigment granules are slightly larger than those of primary and secondary pigment cells. Scale bars: A, B, and D, $4 \mu \mathrm{m} ; \mathrm{C}, 2 \mu \mathrm{m}$.

Towards the distal end of the rhabdom, 7 retinula cells are involved in the formation of the centrally-fused rhabdom, which is circular in outline in both males and females (Figs 4A-D). Transmission electron micrographs of transverse sections showed that at this level retinula cell 1 makes a greater contribution to the formation of the rhabdom than do the other six retinula cells. Unlike the rhabdomeres of the other six retinula cells which are V-shaped, the rhabdomere of cell 1 is triangular. Its microvilli run in parallel directions and appear to be less electron-dense than those of the other 6 rhabdomeres (Figs 4C-D), but no differences in microvillar diameters between any of rhabdomeres could be detected. A few micrometer eye-inward from the distal end of the rhab- dom, retinula cell 8 begins to contribute its rhabdomere to the rhabdom. The rhabdomere of R8 is situated opposite to that of R1, also triangular in shape and less electrondense than the rest. Its microvilli are arranged in a more regular, parallel manner than those of the other 6 rhabdomeres and, moreover, they are oriented in the same direction as those of the rhabdomere of R1 (Figs 4E-F). Altogether 8 retinula cells contribute to the formation of the rhabdom, which proximally appears more "lobed" than distally (Figs 4A-B). The rhabdom reaches its maximum diameter of 7.7-8.1 $\mu \mathrm{m}$ at mid level in both male and female ommatidia (Table 1). This microvillar organization of the rhabdomeres remains unchanged throughout the rest of the rhabdom until the rhabdomeres 

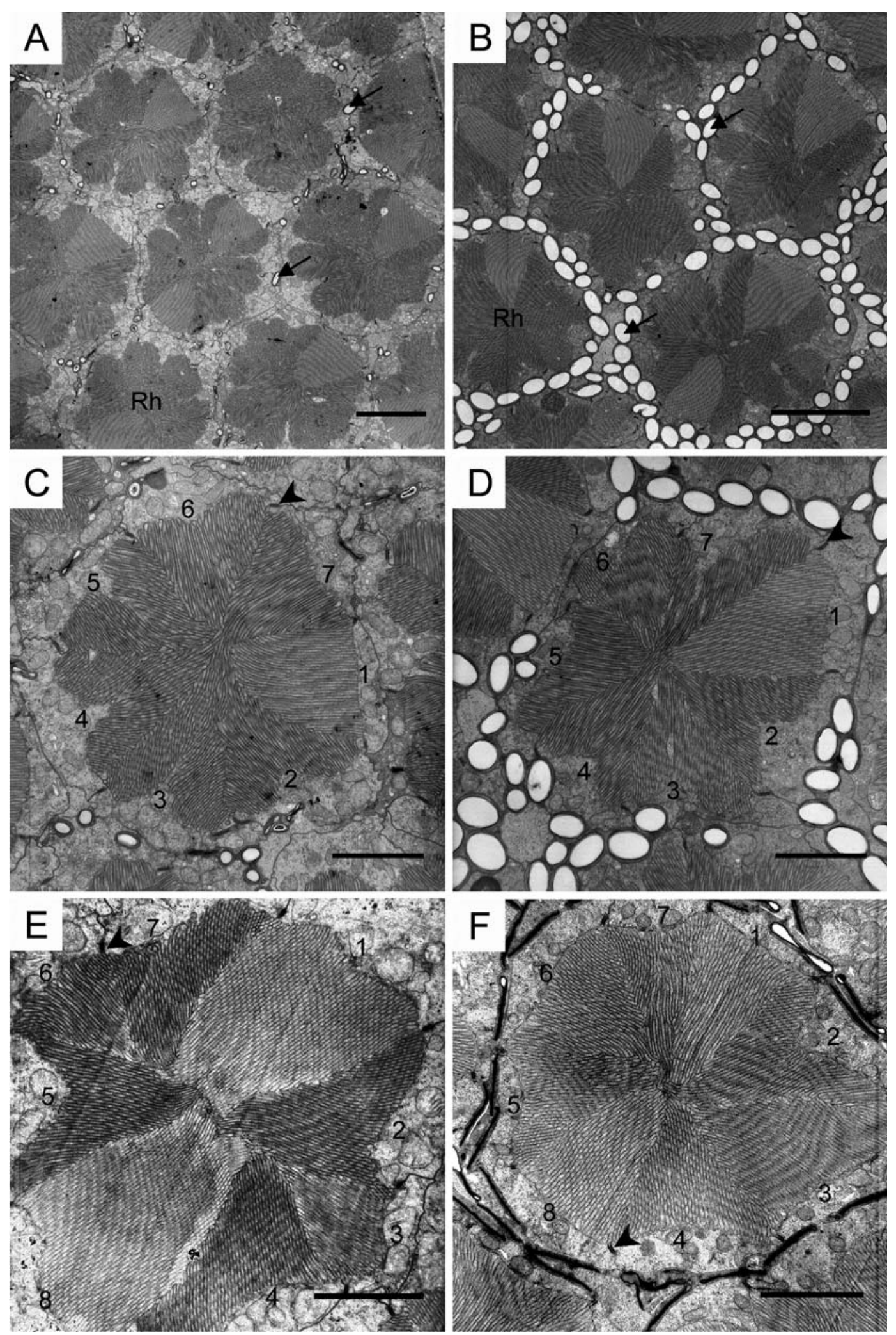

Fig. 4. Transmission electron micrographs of A. ephemerella compound eye. A - transverse sections through the distal region of the rhabdom of the male, B - proximal rhabdom region of the female. Air filled tracheae (arrows) become more numerous as one moves proximally. Note that rhabdoms formed by 7 as well as 8 rhabdomeres can be seen in both sections. Rhabdomeres 1 and 8 can be recognised by their triangular shape and lighter stain. C, D - transverse section through midlevel region of the rhabdom in the eye of a male and a female. Here the two rhabdoms are formed by 7 receptor cells. The rhabdomere of receptor cell 1 is always triangular in shape and less electron dense than the others and its microvilli are always aligned perfectly parallel to each other. E, F transverse section through the midlevel region of the rhabdom in the eye of a male and a female. Here the rhabdoms are formed by 8 receptor cells. Rhabdomeres of both receptor cells 1 and 8 are triangular in shape, less electron dense than the other, and orientated in the same direction. Desmosomes (arrowheads) are developed between adjacent retinula cells. Scale bars: A, B, $4 \mu \mathrm{m} ; \mathrm{C}-\mathrm{F}, 2 \mu \mathrm{m}$. 

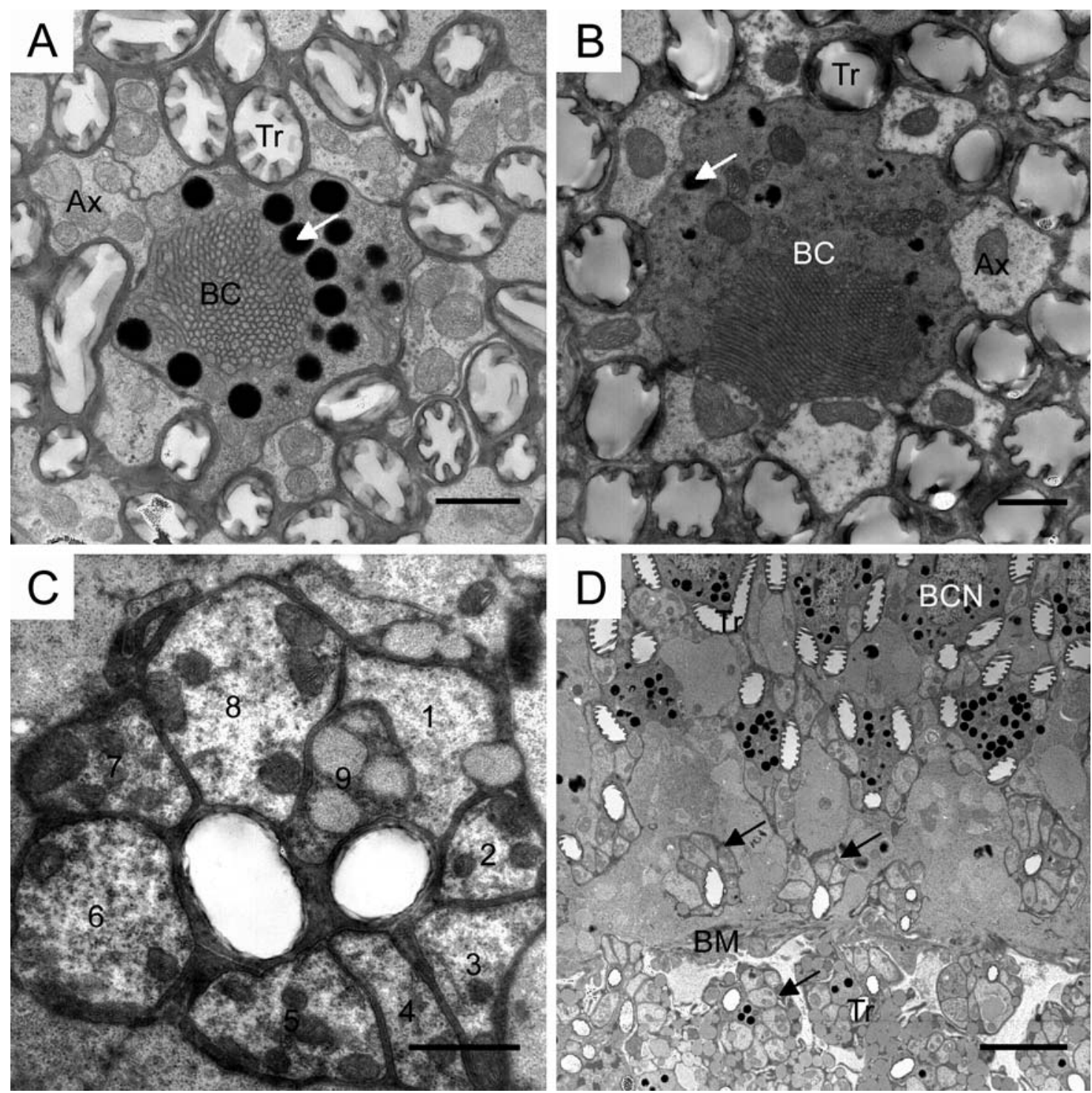

Fig. 5. Transmission electron micrographs of A. ephemerella compound eye. A, B - transverse section through the most proximal rhabdom region of the eye of a male and a female; a ninth (basal) retinula cell (BC) that contains its own screening pigment (white arrow) contributes a small rhabdomere to the rhabdom. At this level the other 8 retinula cells have turned into axons (Ax) surrounding the basal cell. C, D - transverse section through the region of the basement membrane in the eye of a male and a female, showing axon bundles with 9 fibres and the location of the nucleus of the basal retinula cell (BCN). Tracheoles (Tr) and axon bundles (arrow) penetrate the basement membrane (BM) together. Scale bars: A-C, $1 \mu \mathrm{m} ; \mathrm{D}, 4 \mu \mathrm{m}$.

diminish in size and are gradually displaced by the basal cell just above the basement membrane.

The basal cell contains pigment granules and possesses its own small rhabdomere (Figs 5A-B). The diameter of the pigment granules of the basal cell measure around $0.46-0.47 \mu \mathrm{m}$ in both male and female. Finally, nine retinula cells of each ommatidium give rise to distinct bundles of retinula cell axons that penetrate the basement membrane (Figs 5C-D). Other common organelles like mitochondria, endoplasmic reticula, multi-vesicular bodies can be seen in the retinula cells at all rhabdom levels in seemingly equal abundance at both day and night conditions. There are no apparent differences in the abundance of these organelles in light and dark adapted samples of both sexes. The diameters of the microvilli at mid-level measure $68-71 \mathrm{~nm}$ in all of the rhabdomeres of both male and female moths. Desmosomes exist between each pair of adjacent retinula cells. They may provide stabilizing anchor-positions and are developed from the distal end of the retinula cells to the proximal end of the rhabdom just above the basement membrane (Figs 3C, 4C-F).

\section{Light/dark sensoric adaptational changes}

Both male and female eyes show very pronounced pigment translocations and retinula cell body migrations upon light/ dark adaptation. In the light-adapted eyes of both sexes, the pigment granules that belong to the secondary pigment cells invade the clear-zone from the cone region. At the same time, the retinula cell bodies pull away from the cone, leaving the crystalline tract in the region that they occupied earlier (Figs 2B, D). Since the 
retinula cell bodies, when they occupy a position in the proximal region of the clear-zone also contain screening pigment granules, there is then (together with the secondary pigment granules) a massive amount of pigment granules present in the region between the cones and the rhabdom layer (Figs 2B, D). When the eye is in the darkadapted state, the screening pigments cluster densely between the cones, and the retinula cell bodies remain attached to the tips of the cones on the distal side of the clear-zone. This leaves the clear-zone free of pigment granules and creates a relatively wide proximal cone aperture through which more light can enter each ommatidium than during light-adaptation (Figs 2A, C).

In contrast to the migrations of the pigment granules and the retinula cell bodies, other structures within the compound eye remained unresponsive to exposures of different light intensities irrespective of whether male or female eyes. No obvious movements of pigment granules were found within the primary pigment cells. Cone lengths, rhabdom lengths and diameters as well as microvillar diameters remained unchanged under different light/dark conditions in both male and female eyes. Respective relative clear-zone widths, which are 0.21 and 0.19 in male and female eyes, were also found not to be significantly different from each other under different light conditions. The rhabdom occupation ratios (ROR) amounted to $71 \%$ and $65 \%$ in male and female eyes, respectively, and also showed no statistically significant differences under different ambient light conditions (Table 1). As the rhabdoms occupy almost the entire area already in the light-adapted retina, being nearly continuous across all ommatidia with no space available for the rhabdom to expand during dark adaptation, an increase in ROR during dark-adaptation would practically have been impossible.

\section{DISCUSSION}

\section{General organization of male and female eye}

Firstly, in Acentria ephemerella both sexes possess a refracting superposition eye, which is a type of eye that is rather typical of nocturnally-active insect species, but in the sexually dimorphic beetle Rhagophthalmus ohbai (Coleoptera: Rhagophthalmidae) (another holometabolic insect species in which males, but not females are fully winged: Lau \& Meyer-Rochow, 2006) the wingless female has an apposition eye and only the winged males have a superposition eye. The superposition eye is common in insects and crustaceans that live in dim habitats or lead a nocturnal life (Nilsson, 1989). The clearzone in the superposition eye allows light that enters the eye through many facets to be focused on more or less one single photoreceptor in the retina (Land, 1981). In this way superposition eyes have the potential to collect more light than apposition eyes without having to sacrifice resolving power.

Secondly, the corneal outer surfaces of both male and female eyes in $A$. ephemerella are covered with corneal nipples. Corneal nipples are commonly encountered in nocturnal, but not diurnal species of Lepidoptera (Bern- hard et al., 1970). Since corneal nipples can reduce the reflection of light from the surface of the eye, the resulting dull appearance of the eye can provide camouflage to the animal during the day when the animal is inactive (Miller, 1979; Stavenga et al., 2005). It can furthermore increase the intensity of the light available to the eye by about $4 \%$ and in combination with the eye's internal tapetum prevent the formation of "ghost images" on the inside of the cornea (Miller, 1979).

Thirdly, the photoreceptor layer in A. ephemerella is made up of an extensive development of microvilli (which are the photoreceptive membranes of the retina). The average rhabdom occupation ratios, reaching $71 \%$ and $65 \%$ in males and females, respectively, are similar to those of other nocturnally active moths (50-80\%) (Eguchi, 1978). Moreover, the proximal half of the rhabdom is partially surrounded by a dense layer of airfilled tracheaoles, creating a tapetum. Where tapeta are present, they occupy a place near the proximal end of the retina so that light that has passed through the retina once can be reflected back into the rhabdom to give the receptors a second chance to absorb photons (Miller, 1979; Autrum, 1981; Land \& Nilsson, 2002). Although photopigment density in the membranes of the rhabdom microvilli and degree of efficiency of the phototransduction cascade could further improve an eye's visual performance, we possess no data on this aspect for the eye of $A$. ephemerella.

Not only in Lepidoptera (Yagi \& Koyama, 1963; Rutowski, 2000), but also in bees (Jander \& Jander, 2002) and beetles (McIntyre \& Caveney, 1998; Gokan \& Meyer-Rochow, 2000) compound eye sizes were found to be positively correlated with body size. Considering the fact that body length in both male and female $A$. ephemerella is about $10 \mathrm{~mm}$ (Berg, 1942; Buckingham \& Ross, 1981), the eye of $A$. ephemerella cannot be very large. According to Meyer-Rochow \& Gál (2004), when the eye radius is smaller than about $250 \mu \mathrm{m}$, little light intensity enhancement is possible by possessing a clear-zone and the presence of a clear-zone could actually become counter-productive. If one compares the radius of curvature in A. ephemerella $(270 \mu \mathrm{m}$ in males and $240 \mu \mathrm{m}$ in females, Table 1) with that of the beetles studied by Meyer-Rochow \& Gál (2004), the sizes of the eyes in $A$. ephemerella males and females have almost reached the lower limits of benefiting from having a clear-zone.

Meyer-Rochow \& Gál (2004) further concluded that for an eye of a given size, rather than to increase the intensity of the collected light by increasing the width of the clearzone at the expense of the size of other components of the eye, it is more important to retain the functionality of the combination of structural elements making up the eye and this seems to be reflected by especially the male $A$. ephemerella. The males possess significantly longer rhabdoms than do the females (Table 1). The sensitivity, $S$ of an eye to an extended light source (Land, 1981) is defined as $S=$ $(\pi / 4)^{2}(\mathrm{~A} / \mathrm{f})^{2} \mathrm{~d}^{2}\left(1-\exp \left[-k \mathrm{l}_{\mathrm{rh}}\right]\right)$, where $\mathrm{d}$ and $1_{\mathrm{rh}}$ refer to rhabdom diameter and length, respectively. Thus, an ommatidium with a longer rhabdom increases the eye's 
absolute sensitivity. Because of the somewhat larger eye of the male and its wider clear-zone, individual facets need not be enlarged (Table 1): due to the extensive migration of screening pigments and the wide clear-zone at night, the aperture of the dark-adapted eye extends across many facets, making individual facet enlargements unnecessary. Under light-adapted conditions smaller facets, in fact, would provide sharper images than the females' larger facets and males are thus more likely to perceive moving objects more effectively than females, features that would be of greater use to a flying insect than one that moves around on the two-dimensional plane of the water surface.

The dioptric apparatus of the female eye was found to be significantly shorter than that of the male (Table 1). This result agrees with that of Thiele (1971), who compared eyes of aquatic and terrestrial arthropods and showed that aquatic species generally possessed dioptric elements that contained larger facets, but less thick corneal lenses and cone cylinders than terrestrial species. In spittle bugs, in which nymphal instars live in a semiaquatic environment until metamorphosis, there is a 3 fold thickening of the cornea as the terrestrial adult emerges following the final moult (Keskinen \& MeyerRochow, 2004). The reduction of the dioptric apparatus in $A$. ephemerella can, thus, be considered one of the adaptational features of the female to an at least partially aquatic existence under water. Regrettably, no further studies specifically comparing the respective roles of corneal and cone tissues in aquatic and terrestrial arthropod species are available. However, it may be worth mentioning that superposition by reflection rather than refraction (i.e., mirror-optics: Land, 1981) seems almost exclusively linked to a permanently submersed existence and is the dominant form of concentrating a parallel bundle of light onto the retina in the superposition eyes of shrimps and crayfish.

\section{Polarization sensitivity}

Many insects that live in the water or have to locate water to deposit their eggs, are able to recognize aquatic habitats by their polarization characteristics (Schwind, 1991, 1993; Horváth, 1995; Kriska et al., 1998; Bernáth et al., 2002). These insects, unlike those peering into the sky (Labhart \& Meyer, 1999) detect the pattern with blue or UV-sensitive ventrally-placed retinula cells with horizontally aligned microvilli. The arrangement of microvilli in A. ephemerella male and female eyes suggests that their eyes also possess the capacity to analyse the reflected polarized light from a water surface. Firstly, both male and female $A$. ephemerella have an enlarged ventral region (Figs 1A-B) and, secondly, the microvilli of rhabdomere 1 and 8 are aligned in parallel with each other (Figs 4E-F) and, as serial sections have shown, consistently oriented in one and the same direction. The study of the spectral responses in 35 species of Lepidoptera showed that all of the tested eyes had independent UV receptors, regardless of whether they belonged to diurnal of nocturnal species (Eguchi et al., 1982). In the hawkmoth Deilephila elpenor (Schlecht et al., 1978), the
UV receptors are located in the two distal retinula cells of the rhabdom, while the other six receptors with more mid-rhabdom positions are green sensitive. Based on our morphological observation, both rhabdomeres 1 and 8 can be expected, as in the hawkmoth, to be UV sensitive and specialized for the detection of polarized light and this would clearly be of use to the male to find the female's habitat. However, wingless females, already floating on a water surface, would be less dependent on polarization sensitivity, but did not experience any evolutionary pressure to lose the regular microvillus orientation necessary to detect the e-vector. Moreover, winged females do occasionally occur (see below).

\section{Functional adaptation of the male and female eye}

Both male and female $A$. ephemerella exhibit very similar photomechanical changes upon light/dark adaptation. Since nocturnally-active males hide in sheltered areas during the day and the females seldom venture onto the water surface at daytime (Berg, 1942), the migration of the secondary pigment granules together with the migration of the retinula cell bodies into the clear-zone must be seen as a precaution to expose the retina to potentially damaging radiation when the insects are being forced to leave their dark refuges. In contrast, at night, screening pigment granules collectively cluster in distal interommatidial spaces around the cone to expose the proximal half of each crystalline cone, thus effectively increasing the superposition aperture of the eye (Warrant \& McIntyre, 1996). This type of pigment migration together with the movements of the retinula cell bodies has also been found in various other nocturnally-active insects with superposition eyes such as beetles (MeyerRochow \& Horridge, 1975; Labhart et al., 1992), moths (Horridge \& Giddings, 1971; Autrum, 1981) and lacewings (Horridge \& Henderson, 1976). Electrophysiological studies have shown that the longitudinal migration of pigment granules alone can account for an increase in sensitivity of the eye of up to $3 \mathrm{log}$ units (Bernhard \& Ottoson, 1960a, b; Meyer-Rochow \& Horridge, 1975; Rodríguez-Sosa \& Aréchiga, 1982; Warrant \& McIntyre, 1990, 1996). Additional gains stemming from changes in the photo-transduction cascade in extremely dark-adapted superposition eyes from the photoreceptors, can improve the sensitivity of an extremely dark-adapted superposition eye by $6 \log$ units above that of a light-adapted eye (Bernhard \& Ottoson, 1960a, b; Bernhard et al., 1963). This value is much higher than the $2 \log$ unit increase often associated with apposition eyes (cf., Meyer-Rochow, 1974).

At first glance, one might have expected the wing reduction in the female to have resulted also in a greater simplicity of the compound eye when compared with that of the fully-winged male. It seems that flight generally requires compound eyes with a higher degree of visual sensitivity and resolution as there are special requirements for flight navigation and speed control (Srinivasan et al., 1996). Thayer (1992) concluded that wing loss was often associated with various other morphological modifications to the body. Loss of wings changes the animal's 
life-style and thus has to affect, if not the design of the compound eye, then at least its role. Female A. ephemerella are no exception. Their eyes are different, but not necessarily simpler.

Females possess a pair of middle and hindlegs with swimming-hairs, which the male lacks. The modified legs enable the flightless female to swim underwater, but the non-aquatic males cannot dive and only fly above the surface of the water. Even if pheromones bring the sexes together, visual information still has to be important for both males and females. They have to use vision to avoid obstacles and to evade predators, albeit in different environments and this is presumably why some differences between male and female eye structures have begun to manifest themselves in $A$. ephemerella. The differences are not as striking as those seen in other highly sexually dimorphic species and may indicate that the separation of the male and female life styles in A. ephemerella are less ancient than those seen, for instance, in Orgya antiqua (Lau \& Meyer-Rochow, 2007) or some bag moths. Pyralid moths, as a whole, seem to date back no further than 55 million years (Speidel, 2003) and the fact that occasionally fully winged $A$. ephemerella females appear in the same area as the wingless females underscores the conclusion of a relatively recent evolution of micropterous aquatic females in $A$. ephemerella. At the same time we may predict that as males and females continue to diverge and increasingly evolve morphologies to suit their respective habitats (the aerial, terrestrial habitat for the males and the dim underwater habitat for the females) eye structural differences will deepen further in the future.

ACKNOWLEDGEMENTS. We are grateful to C. Feldbaum and O. Miler (both of the Limnological Institute of the University of Konstanz) for technical assistance in the laboratory and help with collections of pupae in the field, respectively. We also express our gratitude to the Electron Microscope Unit, run by W. Heyser of the University of Bremen, for access to their facilities and $\mathrm{TF}(\mathrm{S}) \mathrm{L}$ and VBM-R further acknowledge the financial support granted to them for field trips to Konstanz by the Jacobs University Bremen.

\section{REFERENCES}

Autrum H. 1981: Light and dark adaptation in invertebrate. In Autrum H. (ed.): Handbook of Sensory Physiology. Vol. VII/6C. Springer, Berlin, pp. 1-91.

Batra S.W.T. 1977: Bionomics of the aquatic moth, Acentria niveus (Oliver), a potential biological control agent for Eurasian watermilfoil and Hydrilla. N. Y. Entomol. Soc. 85: 59-139.

BerG K. 1942: Contribution to the biology of the aquatic moth Acentropus niveus (Oliv.). Vidensk. Medd. Dansk. Naturh. Foren. 105: 59-139.

Bernáth B., Szedenics G., Wildermuth H. \& Horváth G. 2002: How can dragonflies discern bright and dark waters from a distance? The degree of polarization of reflected light as a possible cue for dragonfly habitat selection. Freshwater Biol. 47: 1707-1719.

Bernhard C.G. \& Ottoson D. 1960a: Comparative studies on dark adaptation in the compound eyes of nocturnal and diurnal Lepidoptera. J. Gen. Physiol. 44: 195-203.
Bernhard C.G. \& Ottoson D. 1960b: Studies on the relation between the pigment migration and the sensitivity changes during dark adaptation in diurnal and nocturnal Lepidoptera. J. Gen. Physiol. 44: 205-215.

Bernhard C.G., Höglund G. \& Ottoson D. 1963: On the relation between pigment position and light sensitivity of the compound eye in different noctural insects. J. Insect Physiol. 9: $573-586$.

Bernhard C.G., Gemne G. \& Sällström J. 1970: Comparative ultrastructure of corneal surface topography in insects with aspects on phylogenesis and function. Z. Vergl. Physiol. 67: $1-25$.

Buckingham G.R. \& Ross B.M. 1981: Notes on the biology and host specificity of Acentria nivea (= Acentropus niveus). $J$. Aquat. Plant Manag. 19: 32-36.

Caveney S. \& McIntyre P. 1981: Design of graded-index lenses in the superposition eyes of scarab beetles. Phil. Trans. Soc. Lond. (B) 294: 589-632.

Denis J.N. \& Schiffermüller C.M. 1775: Ankündigung eines systematischen Werkes von den Schmetterlingen der Wienergegend. Bernardi, Wien, $322 \mathrm{pp}$.

EGUCHI E. 1978: Comparative fine structure of Lepidopteran compound eyes, especially Skippers (Hesperioidea). Zool. Mag. 87: 32-43.

Eguchi E., Watanabe K., Hariyama T. \& Yаmamoto K. 1982: A comparison of electrophysiologically determined spectral responses in 35 species of Lepidoptera. J. Insect Physiol. 28: 675-682.

Gokan N. \& Meyer-Rochow V.B. 2000: Morphological comparisons of compound eyes in Scarabaeoidea (Coleoptera) related to the beetles' daily activity maxima and phylogenetic positions. J. Agricult. Sci. 45: 15-61.

Gross E.M., JoHnson R.L. \& Hairston JR.N.G. 2001: Experimental evidence for changes in submersed macrophyte species composition caused by the herbivores Acentria ephemerella (Lepidoptera). Oecologia 127: 105-114.

Gross E.M., Feldbaum C. \& ChOI C. 2002: High abundance of herbivorous Lepidoptera larvae (Acentria ephemerella Denis $\&$ Schiffermüller) on submersed macrophytes in Lake Constance (Germany). Arch. Hydrobiol. 155: 1-21.

HACKMAN W. 1966: On wing reduction and loss of wings in Lepidoptera. Notul. Entomol. 46: 1-16.

HEPPNER J.B. 1991: Brachyptery and aptery in Lepidoptera. Trop. Lepid. 2: 11-40.

Hornstein E.P., O’Carroll D.C., Anderson J.C. \& Laughlin S.B. 2000: Sexual dimorphism matches photoreceptor performance to behavioural requirements. Proc. R. Soc. Lond. (B) 267: 2111-2117.

Horridge G.A. \& Giddings C. 1971: The retina of Ephestia (Lepidoptera). Proc. R. Soc. Lond. (B) 179: 87-95.

Horridge G.A. \& Henderson I. 1976: The ommatidium of the lacewing Chrysopa (Neuroptera). Proc. R. Soc. Lond. (B) 192: 259-271.

HoRvÁth G. 1995: Reflection-polarization patterns at flat water surfaces and their relevance for insect polarization vision. $J$. Theor. Biol. 175: 27-37.

JANDER U. \& JANDER R. 2002: Allometry and resolution of bee eyes (Apoidea). Arthrop. Struct. Dev. 30: 179-193.

Johnson R.L., Gross E.M. \& Hairston JR.N.G. 1998: Decline of the invasive submersed macrophyte Myriophyllum spicatum (Haloragaceae) associated with herbivory by larvae of Acentria ephemerella. Aquat. Ecol. 31: 273-282.

KrisKa G., Horváth G. \& Andrikovics S. 1998: Why do mayflies lay their eggs en masse on the dry asphalt roads? Water- 
imitating polarized light reflected from asphalt attracts Ephemeroptera. J. Exp. Biol. 201: 2273-2286.

Keskinen E. \& Meyer-Rochow V.B. 2004: Post-embryonic photoreceptor development and dark/light adaptation in the spittle bug Philaenus spumarius (L.) (Homoptera: Cercopidae). Arthrop. Struct. Dev. 33: 405-417.

LABHART T. \& MeYer E.P. 1999: Detectors for polarized skylight in insects: A survey of ommitidial specializations in the dorsal rim area of the compound eye. Microsc. Res. Tech. 47: 368-379.

Labhart T., Meyer E.P. \& Schenker L. 1992: Specialized ommatidia for polarization vision in the compound eye of cockchafers, Melolontha melolontha, (Coleoptera: Scarabaeidae). Cell Tissue Res. 268: 419-429.

LAND M.F. 1981: Optics and vision in invertebrates. In Autrum H. (ed.): Handbook of Sensory Physiology. Vol. VII/6B. Springer-Verlag, Berlin, Heidelberg, NewYork, pp. 471-592.

LAND M.F. \& NiLsson D.E. 2002: Animal Eyes. Oxford University Press, Oxford, $221 \mathrm{pp}$.

LaU T.F.S. \& Meyer-Rochow V.B. 2006: Sexual dimorphism in the compound eye of Rhagophthalmus ohbai (Coleoptera: Rhagophthalmidae). J. Asia-Pacific Entomol. 9: 1-12.

Lau T.F.S. \& Meyer-Rochow V.B. 2007: Sexual dimorphism and light/dark adaptation in the compound eye of Orygia antiqua (Lepidoptera: Lymantriidae). Eur. J. Entomol. 104: 247-258.

McIntyre P. \& Caveney S. 1998: Superposition optics and the time of flight in onitine dung beetles. J. Comp. Physiol. (A) 183: $45-60$.

Merry J.W., Morehouse N.I., Yturralde K. \& Rutowski R.L. 2006: The eye of a patrolling butterfly: Visual field and eye structure in the orange sulphur, Colias eurytheme (Lepidoptera: Pieridae). J. Insect Physiol. 52: 240-248.

MeYer-Rochow V.B. 1974: Fine structural changes in dark-light adaptation in relation to unit studies of an insect compound eye with a crustacean-like rhabdom. J. Insect Physiol. 20: 573-589.

Meyer-Rochow V.B. \& Horridge G.A. 1975: The eye of Anoplognathus (Coleoptera: Scarabaeidae). Proc. R. Soc. Lond. (B) 188: 1-30.

Meyer-Rochow V.B. \& GÁL J. 2004: Dimensional limits for arthropod eyes with superposition optics. Vision Res. 44: 2213-2223.

Miller W.H. 1979: Ocular optical filtering. In Autrum H. (ed.): Handbook of Sensory Physiology. Vol. VII/6A. Springer, Berlin, pp. 69-143.

Moser J.C., Reeve J.D., Bento J.M.S., Lucia T.M.C., Cameron R.S. \& HECK N.M. 2004: Eye size and behaviour of day- and night-flying leafcutting ant alates. J. Zool. Lond. 264: 69-75.

Nilsson D.E. 1989: Optics and evolution of the compound eye. In Stavenga D.G. \& Hardie R.C. (eds): Facets of Vision. Springer-Verlag, Berlin, Heidelberg, pp. 30-73.
Rodriguez-Sosa L. \& ARÉCHIGA H. 1982: Range of modulation of light sensitivity by accessory pigments in the crayfish compound eye. Vision Res. 22: 1515-1524.

RofF D.A. \& Fairbairn D.J. 1991: Wing dimorphisms and the evolution of migratory polymorphism among Insecta. Am. Zool. 31: 243-251.

RUTOWSKi R.L. 2000: Variation of eye size in butterflies: interand intraspecific patterns. J. Zool. Lond. 252: 187-195.

Schlecht P., Hamdorf K. \& Langer H. 1978: The arrangement of colour receptors in a fused rhabdom of an insect: A microspectrophotometric study on the moth Deilephila. J. Comp. Physiol. 123: 239-243.

SchwIND R. 1991: Polarization vision in water insects and insects living on a moist substrate. J. Comp. Physiol. (A) 169: 531-540.

Schwind R. 1993: Reflection-polarization pattern at water surfaces and correction of a common representation of the polarization pattern of the sky. Naturwissenschaften 80: 82-83.

SPEIDEL W. 2003: Aquatische Schmetterlinge: Phylogenie und Lebensweise einer Microlepidopterengruppe (Lepidoptera: Crambidae). Verh. Westd. Entomol.-Tag., Löbbecke-Mus. Düsseldf. 2001: 81-87.

Srinivasan M.V., Zhang S.W., Lehrer M. \& Collett T.S. 1996: Honeybee navigation en route to the goal: visual flight control and odometry. J. Exp. Biol. 199: 237-244.

Stavenga D.G., Foletti S., Palasantzas G. \& Arikawa K. 2005: Light on the moth-eye corneal nipple array of butterflies. Proc. R. Soc. (B) 273: 661-667.

THAYER M.K. 1992: Discovery of sexual dimorphism in Staphylinidae (Coleoptera): Omalium flavidum, and a discussion of wing dimorphism in insects. J. N. Y. Entomol. Soc. 100: 540-573.

THIELE H. 1971: Über die Facettenaugen von land- und wasserbewohnenden Crustaceen. Z. Morphol. 69: 9-22.

Viloria A.L., Pyrcz T.W., Wojtusiak J., Ferrer-Paris J.R., Beccaloni G.W., Sattler K. \& Lees D.C. 2003: A brachypterous butterfly? Proc. R. Soc. Lond. (B) (Suppl.) 270: S21-S24.

WarRant E.J. \& McInTYRe P. 1990: Screening pigments, aperture and sensitivity in the dung beetles superposition eye. $J$. Comp. Physiol. 167: 805-815.

WARRANT E.J. \& McInTYRe P. 1996: The visual ecology of pupillary action in superposition eyes. J. Comp. Physiol (A) 178: $75-90$.

Yagi N. \& Koyama N. 1963: The Compound Eye of Lepidoptera: Approach from Organic Evolution. Shinkyo Press, Tokyo, $318 \mathrm{pp}$.

Zera A.J. \& Denno R.F. 1997: Physiology and ecology of dispersal polymorphism in insects. Annu. Rev. Entomol. 42: 207-230.

Received November 3, 2006; revised and accepted January 17, 2007 


\section{ERRATUM}

In our recent publication:

Lau T.F.S., Gross E.M. \& Meyer-Rochow V.B. 2007: Sexual dimorphism and light/dark adaptation in the compound eyes of male and female Acentria ephemerella (Lepidoptera: Pyraloidea: Crambidae). Eur. J. Entomol. 104: 459-470.

the reference

SCHwind R. 1993: Reflection-polarization pattern at water surfaces and correction of a common representation of the polarization pattern of the sky. Naturwissenschaften 80: 82-83.

fails to mention the co-author of that paper and, thus, should have been

Schwind R. \& Horvath G. 1993: Reflection-polarization pattern at water surfaces and correction of a common representation of the polarization pattern of the sky. Naturwissenschaften 80: 82-83.

We regret this oversight of ours and apologize to the authors.

Ting Fan (Stanley) LAU, Elisabeth Maria GROSS and Victor Benno MEYER-ROCHOW 